\title{
AVALIAÇÃO DA FRAGILIDADE AMBIENTAL NA MICROBACIA DO RIACHO CAJAZEIRAS NO SEMIÁRIDO POTIGUAR
}

\author{
ENVIRONMENTAL VULNERABILITY EVALUATION IN CAJAZEIRAS CREEK \\ WATERSHED IN THE POTIGUAR SEMIARID
}

\section{EVALUACIÓN DE LA FRAGILIDAD AMBIENTAL DE LA CUENCA DEL ARROYO CAJAZEIRAS EN EL SEMIÁRIDO POTIGUAR}

\author{
José Pio Granjeiro Batista - Universidade Federal do Rio Grande do Norte - Natal \\ - Rio Grande do Norte - Brasil \\ bradpio10@gmail.com \\ Fernando Moreira da Silva - Universidade Federal do Rio Grande do Norte - Natal \\ - Rio Grande do Norte - Brasil \\ fmoreira@ufrnet.br
}

\section{Resumo}

0 presente artigo analisa a fragilidade ambiental na microbacia do riacho Cajazeiras localizada na mesorregião do Oeste potiguar. A pesquisa utiliza como base a concepção integrada da paisagem de Tricart (1977), Bertrand (2004), Sotchava (1978), Ross (1994, 2003, 2009), Crepani (2008), Ab'Saber (1969, 1999), utilizando técnicas de geoprocessamento para a análise do geossistema na identificação da fragilidade ambiental dos componentes da paisagem, tais como clima, relevo, geologia, pedologia, geomorfologia e uso e ocupação do solo. Os resultados mostram que a paisagem da microbacia apresenta fragilidade ambiental média e alta em toda sua área, destacando-se as margens da rede fluvial, causada pelo uso e ocupação para a agropecuária e pela ocupação de áreas urbanas da cidade de Pau dos Ferros. Nesse contexto, torna-se urgente uma política de gestão territorial que considere a bacia hidrográfica como célula de planejamento e que construa um plano de uso e ocupação do solo compatível com a realidade ambiental e social, considerando as várias racionalidades e os princípios democráticos.

Palavras-chave: fragilidade, paisagem, microbacia.

\section{Abstract}

This article analyzes the environmental fragility in Cajazeiras Creek Watershed located in West Potiguar. The research was based on the landscape integrated conception of Tricart (1977), Bertrand (2004), Sotchava (1978), Ross (1994, 2003, 2009), Crepani (2008), Ab'Saber (1999, 1969), using geoprocessing techniques to analyze the geosystem, focusing on the identification of environmental fragility of landscape components such as climate, relief, geology, pedology, geomorphology and soil use and occupation. The results show that the watershed landscape has medium and high environmental fragility throughout its area, especially on the riverbanks, due to the areas use and occupation for farming and for Pau dos Ferros City urban areas occupation. In this context, it is necessary, the creation of a regional policy for supporting territorial management that considers the watershed as a planning cell, and the development of a plan for the soil use and occupation, compatible with the environmental and social realities, considering the various democratic principles.

Key words: environmental fragility, landscape, watershed. 
Resumen

En este artículo se analiza la fragilidad ambiental de la Cuenca del Arroyo Cajazeiras ubicada en la región ocidental potiguar. La investigación se basó en el diseño integrado del paisaje de Tricart (1977), Bertrand (2004), Sotchava (1978), Ross (1994, 2003, 2009), Crepani (2008), Ab'Saber (1999, 1969), usando técnicas SIG para el análisis de geosistema en la identificación de la fragilidad ambiental de los componentes del paisaje, tales como el clima, topografía, geología, edafología, geomorfología y uso de la tierra y del suelo. Los resultados muestran que el paisaje de la cuenca tiene fragilidad ambiental media y alta a lo largo de su área, especialmente en los bancos de la red fluvial, determinada por el uso y la ocupación para las zonas agrícolas y urbanas de la ciudad de Pau dos Ferros. En este contexto, se convierte en política urgente una gestión de la tierra que considere la cuenca como una célula de planificación e que construya un plan de uso de la tierra compatible con el desarrollo ambiental y social, teniendo en cuenta las diferentes motivaciones y los principios democráticos.

Palabras clave: fragilidad, paisaje, cuenca.

\section{Introdução}

A sociedade vive uma crise paradigmática determinada, principalmente, pelo sistema capitalista pautado no individualismo e no materialismo, ou seja, numa racionalidade formal e instrumental que regula o controle da natureza e da sociedade. Isso acaba potencializando a fragilidade dos diversos geosssistemas, provocando graves problemas sociais e ambientais. Esse processo interfere nos ambientes naturais criando novas situações, construindo e reordenando os espaços físicos com a implantação de cidades, estradas, atividades agrícolas, instalações de barragens e retificações de canais fluviais. Essas atividades resultam em alterações que modificam o equilíbrio da natureza. De acordo com Ross (2003, p. 12), a natureza "não é estática, mas [...] apresenta quase sempre um dinamismo harmonioso em evolução estável e contínua, quando não afetada pelos homens".

Nesse contexto, faz-se necessário tomar decisões que busquem um melhor equilíbrio entre sociedade e natureza, estruturado na sustentabilidade geossistêmica, tendo a bacia hidrográfica como célula importante de análise e planejamento territorial.

Desse modo, o presente trabalho analisa a fragilidade ambiental, na perspectiva integrada da paisagem, causada pelas próprias condições naturais somadas à contribuição das ações antrópicas, provocadas pelo uso e ocupação do solo, na microbacia do riacho Cajazeiras no semiárido potiguar. A fragilidade do ambiente foi classificada segundo a metodologia empregada por Ross $(1994,2003)$, que define o grau de fragilidade em duas variáveis: fragilidade ambiental potencial, definida pelos elementos 
físicos da paisagem (clima, geologia, geomorfologia, pedologia), e fragilidade ambiental emergente, definida pelos elementos físicos somados ao uso e à ocupação do solo.

Nessa perspectiva, os elementos da paisagem foram integrados da seguinte forma: o clima está relacionado à quantidade e à intensidade da pluviometria; a geologia refere-se à coesão representada pelos tipos de rochas; a geomorfologia depende do grau de declividade proporcionado pelo relevo; a pedologia depende das características físicas e minerais do solo e de sua capacidade de resiliência diante dos processos naturais e das ações antrópicas. Em relação ao uso e à ocupação do solo, foi considerado o grau de proteção do terreno assim distribuído: alta proteção nas áreas de floresta densa; média proteção para as áreas de vegetação de caatinga esparsa; baixa proteção nas áreas urbanas com planejamento inadequado, nas atividades agropecuárias e nas áreas com presença de solo exposto.

\section{Caracterização da área de estudo}

A microbacia do riacho Cajazeiras faz parte da sub-bacia hidrográfica do rio Encanto e da bacia do Rio Apodi-Mossoró, ambas pertencentes à região hidrográfica do atlântico nordeste oriental brasileiro, situada na mesorregião do Oeste potiguar e nas microrregiões da Serra de São Miguel e Pau dos Ferros, possuindo uma área de drenagem de 116,8 km², que abrange quatro municípios: Encanto, Pau dos Ferros, Água Nova e Rafael Fernandes.

A hidrografia da microbacia caracteriza-se pela intermitência de suas águas, tendo como principais afluentes o riacho Cachoeirinha, o riacho da Favela, o riacho dos Estevãos e o riacho Boa Sorte. Além disso, a microbacia apresenta grande quantidade de açudes, destacando-se o Açude 25 de Março, dentro da área urbana da cidade de Pau dos Ferros, e o açude das Maretas localizado na zona rural do município de Rafael Fernandes (Figura 1).

Segundo a CPRM (2005), na área de estudo dominam rochas do Complexo Jaguaretama representadas por ortognaisses e migmatitos de composição tonalítica a granodiorítica e granítica, com intercalações de gnaisses anfibolíticos. Ocorre, ainda, uma pequena área com incidência da suíte Serra do Deserto caracterizada por ortognaisses grandioríticos e graníticos. Em relação à geomorfologia, a microbacia está inserida na 
Depressão Sertaneja e no Planalto da Borborema, em que as altitudes variam entre 200 a $600 \mathrm{~m}$, tendo como principal divisor de águas a Serra do Bom Será, localizada nos municípios de Encanto, Rafael Fernandes e Água Nova.

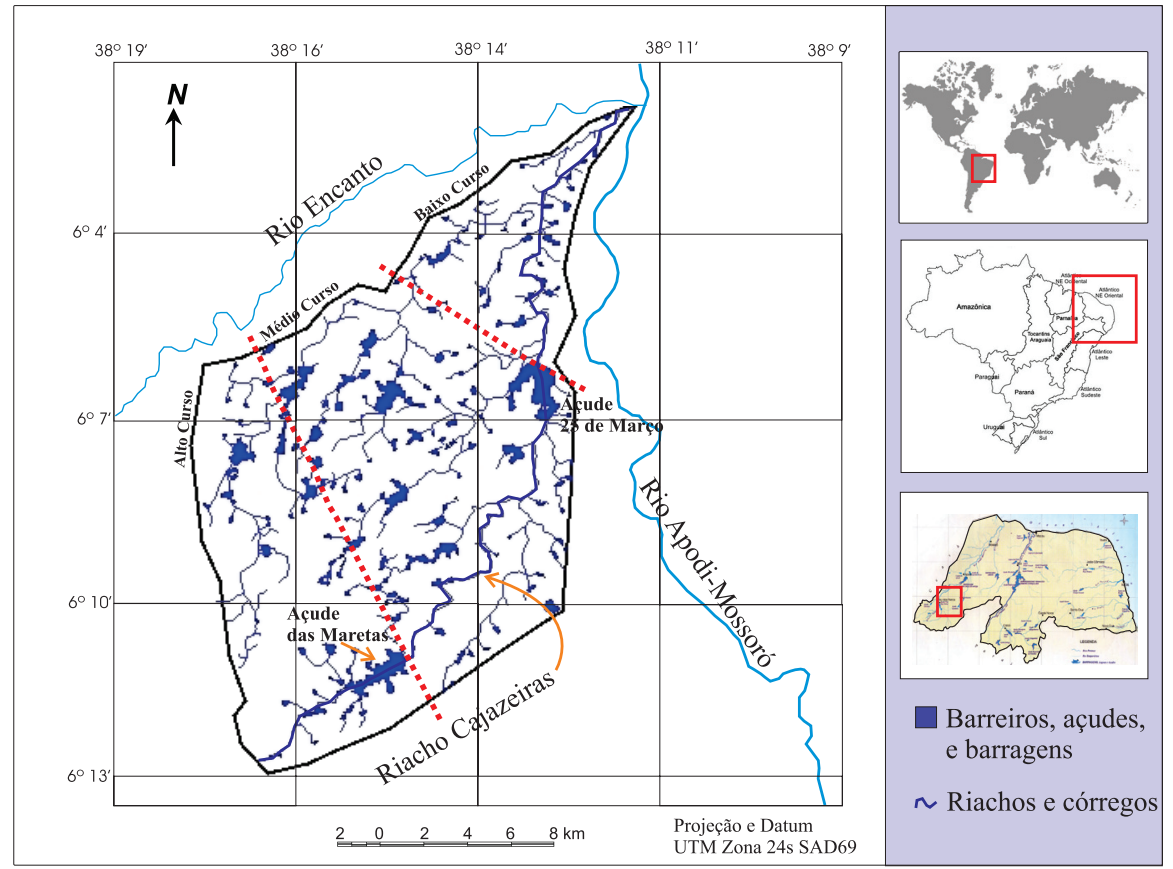

Figura 1 - Localização da Bacia Hidrográfica do riacho Cajazeiras, RN.

Fonte: Baseado na malha do IBGE. Adaptado pelo autor (2010).

Os solos predominantes na área são: Neossolos, Neossolos Litólicos, Luvissolos e Argissolos Vermelho-Amarelo (Embrapa, 2005). Segundo a classificação de Köppen-Geiger, o clima da área é tropical semiárido na maior parte da microbacia, exceto no seu alto curso, cujo clima é tropical subúmido seco, devido à altitude dos contrafortes da Serra da Borborema.

\section{Procedimentos metodológicos}

A presente pesquisa foi sistematizada em fases distintas contemplando: coleta de dados primários e secundários; trabalho de gabinete; 
reconhecimento e visitas na área de estudo; trabalho de campo com a aplicação de entrevistas; levantamento fotográfico com registro de coordenadas geográficas utilizando GPS; e elaboração de mapas da paisagem utilizando técnicas de geoprocessamento com auxílio dos Sistemas de Informações Geográficas (SIG).

Para fazer a análise da paisagem da microbacia do riacho Cajazeiras utilizou-se a visão integrada da paisagem na perspectiva de Tricart (1977), Ab’Saber (1999, 1969), Ross (1994, 2003 e 2009) Crepani (2008), Sotachava (1978), Bertrand (2004). Já para a análise da fragilidade ambiental potencial e emergente da paisagem da microbacia do riacho Cajazeiras, foram considerados os levantamentos de dados realizados em gabinete e em campo, utilizando cartas topográficas, geológicas, geomorfológicas, pedológicas e imagens de satélite. A pesquisa foi orientada por cartas nas escalas de 1:50.000, 1:100.000 e 1:200.000). No entanto, os mapas temáticos foram elaborados na escala de 1:100.000. Também foram utilizados os softwares Spring 5.1.5 e o CorelDraw.

A espacialização das informações baseou-se em diversas fontes como o IBGE, a Embrapa, o CPRM, a classificação de Koppen-Geiger e a classificação do relevo de Ross (2003). Na construção do mapa de uso do solo foram utilizadas técnicas de geoprocessamento com a segmentação e a classificação da imagem Landsat, considerando o comportamento da paisagem e as unidades de usos selecionadas: caatinga densa, caatinga esparsa, agropecuária, corpos d'agua, solo exposto e solo urbano.

Com o resultado da análise integrada e da superposição das informações acerca da estrutura climática, geológica, geomorfológica (declividade), pedológica, hidrológica e do uso e ocupação do solo na microbacia, foi confeccionado um mapa-síntese com os graus de fragilidade ambiental, potencial e emergente, distribuídos em três níveis: fragilidade baixa (peso 1), fragilidade média (peso 2) e alta (peso 3).

\section{Referencial teórico}

\section{Análise integrada da paisagem e fragilidade ambiental}

Segundo Rodriguez e Silva (2002), uma visão global das interações da natureza com a sociedade na academia iniciou-se no final do século XVIII e início do século XIX, com os trabalhos de Kant, Humboldt e Rit- 
ter. Período no qual se destacaram duas correntes no contexto da Geografia: uma com a visão voltada para a Natureza, pautada na Geografia Física (principalmente com as concepções de Humboldt e Dokuchaev), e outra com a visão centrada nas questões humanas (Geografia Humana ou a Antropogeografia) de Karl Ritter.

Outra corrente determinou o surgimento da Ecologia como disciplina biológica nos finais do século XIX, com ênfase aos estudos das relações entre o meio físico-químico e os seres vivos. Entretanto, o conceito de ecossistema só veio a surgir em 1935 sob influência da concepção da Teoria Geral de Sistemas. Destaca-se, também, a Geoecologia das Paisagens de Karl Troll, surgida nos anos de 1930, que analisava funcionalmente a paisagem integrando o social e o ecológico.

A teoria geossistêmica surge na década de 1960 com o especialista siberiano Victor Sotchava, sob a ótica das paisagens (Landschaft) e fundamentada na Teoria Geral de Sistemas. O desenvolvimento da visão integrada da paisagem na União Soviética e no leste europeu deve-se a duas condições: o uso do Marxismo e do pensamento de Lênin, como doutrina oficial de cunho dialético materialista; e a necessidade de planificação estatal dos países "socialistas", que precisavam conhecer as unidades naturais de forma integrada, para melhor controlá-las.

A partir dos anos 70 do século XX, a análise da paisagem de forma integrada ganha destaque com a Ecogeografia desenvolvida por Jean Tricart, que considera as unidades ecodinâmicas como sistemas ambientais por excelência, tendo a Geomorfologia como elemento central de estudo. Vale salientar que, desde sua formação, a ciência Geográfica tem buscado métodos que permitam melhor compreender e analisar os diversos elementos e processos que compõem as paisagens sob uma ótica mais integradora.

No presente estudo utiliza-se a perspectiva teórica geossistêmica, que integra os elementos da paisagem e subsidia o entendimento dos fenômenos de forma mais abrangente, considerando os elementos naturais e artificiais e a ação antrópica. Desse modo, destaca-se o uso da cartografia e de técnicas de geoprocessamento na identificação e na análise do grau de fragilidade dos ambientes. Tais estudos são de suma importância para tentar mitigar a degradação. De acordo com Ross (1994, p. 2),

os estudos relativos à fragilidade, expressos através de cartogramas e textos, são documentos de extrema importância ao Planejamento 
Ambiental, que tenha como centro de preocupação o desenvolvimento sustentado, onde conservação e recuperação ambiental estão lado a lado com o desenvolvimento econômico e social.

Segundo Ross (2009), a fragilidade ambiental é a perda do estado "clímax" em que os processos mecânicos atuam em equilíbrio dinâmico, predominando a pedogênese em detrimento da morfogênese; ou melhor, com essa fragilidade a perda do potencial ambiental repercute no desenvolvimento social da área. Ainda conforme o autor, a fragilidade diz respeito à quebra do potencial ecológico de um geossistema diretamente relacionado com as condições do meio físico natural, principalmente com a cobertura vegetal, e revela o potencial de degradação provocada pelas atividades antrópicas.

Contudo, a presente pesquisa ateve-se aos referenciais discutidos e à aplicação da metodologia proposta por Ross (1994, 2003), para analisar a paisagem da microbacia do riacho Cajazeiras.

\section{Resultados e discussões}

\section{Fragilidade ambiental potencial}

A fragilidade ambiental potencial caracteriza-se pela fragilidade natural de um determinado espaço que está submetido à capacidade de resiliência dos solos (erosão), do clima (intensidade e pluviometria), da geomorfologia (declividade do relevo), da geologia (coesão das rochas), que indicam o equilíbrio ou desequilíbrio natural. Desse modo, ao analisar os ambientes sob a ótica da fragilidade potencial são considerados apenas os aspectos naturais. Nessa perspectiva, Tricart (1977) destaca que, para analisar o equilíbrio dinâmico da paisagem, é necessário criar unidades ou tipos que denominou de unidades ecodinâmicas, classificadas em: meios estáveis, meios fortemente instáveis e meios intergrades.

Na microbacia do riacho Cajazeiras, a fragilidade potencial foi analisada com a superposição dos mapas de clima (Figura 2), geologia (Figura 3), geomorfologia e pedologia. O clima é um dos fatores mais importantes na formação da paisagem, porque atua de forma contundente nos processos pedológicos, geomorfológicos, geológicos, hidrográficos, florístico e faunístico. Nas regiões semiáridas o clima tem sido um "fator determinante” na formação da paisagem. De acordo com Ab’Saber (1999, p. 13), 
há muito outros fatores que respondem pela marcante originalidade no Nordeste seco a começar pelo fato de que elas ocupam posição geográfica anômala, mais próxima do Equador do que dos trópicos. O ritmo do clima regional, porém, continua sendo tropical, com duas estações bem marcadas: uma muito seca, outra moderamente chuvosa, cuja continuidade, entretanto, como vimos, está sujeita a fortes rupturas ao longo dos anos. Podem ocorrer anos muito secos e eventuais períodos de grandes chuvas, com inundações catastróficas.

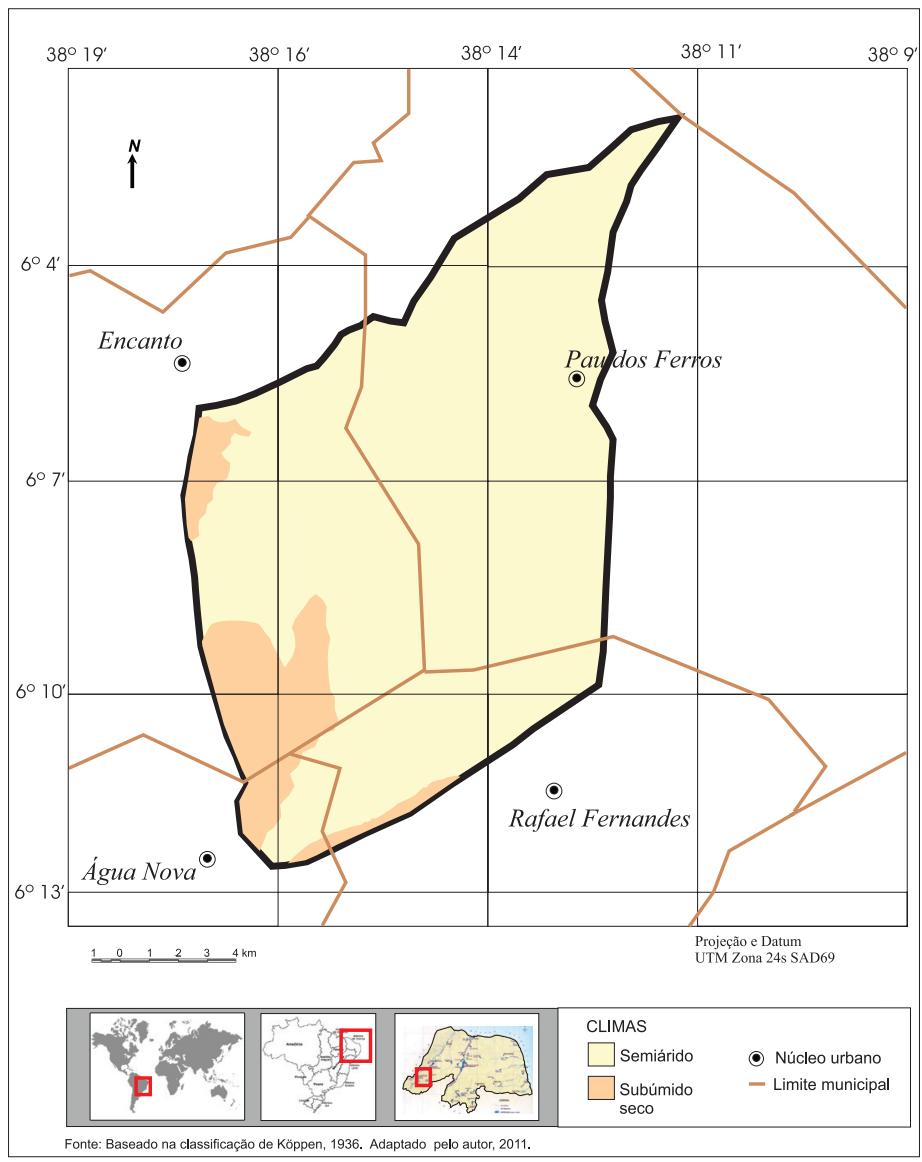

Figura 2 - Climas da microbacia do riacho Cajazeiras, RN, 2011. 


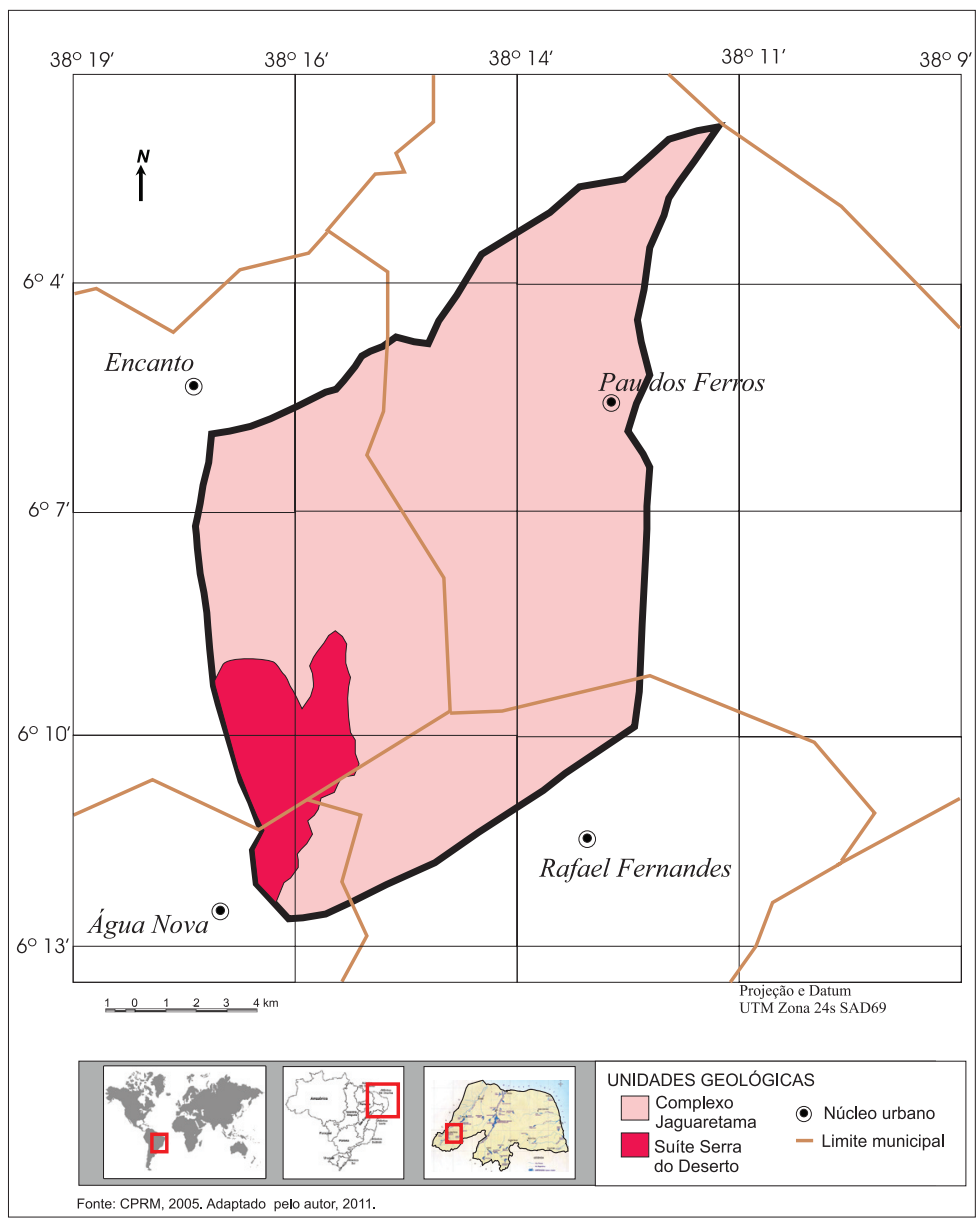

Figura 3 - Geologia da microbacia do riacho Cajazeiras, RN, 2011.

A fragilidade do clima está relacionada à pluviosidade total, à intensidade pluviométrica e à distribuição sazonal. Entretanto, a característica mais importante é a intensidade pluviométrica, que está diretamente relacionada à quantidade de precipitação e ao tempo dessa precipitação. Nesse caso, onde predomina uma pluviometria bem distribuída e não torrencial durante todo o ano, o poder erosivo é bem menor do que onde predomina uma distribuição irregular, concentrada e torrencial em um único período temporal, que causa um processo erosivo mais intenso. 
No entanto, como aponta os estudos de Ab'Saber (1969), Ross (1994, 2003), Tricart (1977), Nunes (2006) e Bigarella (2003), as variações do clima global no Período Terciário e Quaternário foram responsáveis pela dinâmica da paisagem no semiárido, caracterizando as serras testemunhos, também chamadas de "inselbergues". Segundo esses autores o clima oscilou entre clima tropical quente e úmido e clima tropical semiárido, intensificando os processos pedogenéticos. Um exemplo é a descontinuidade do relevo proporcionada pelas serras, serrotes e inselbergues nessa região (Figura 4).

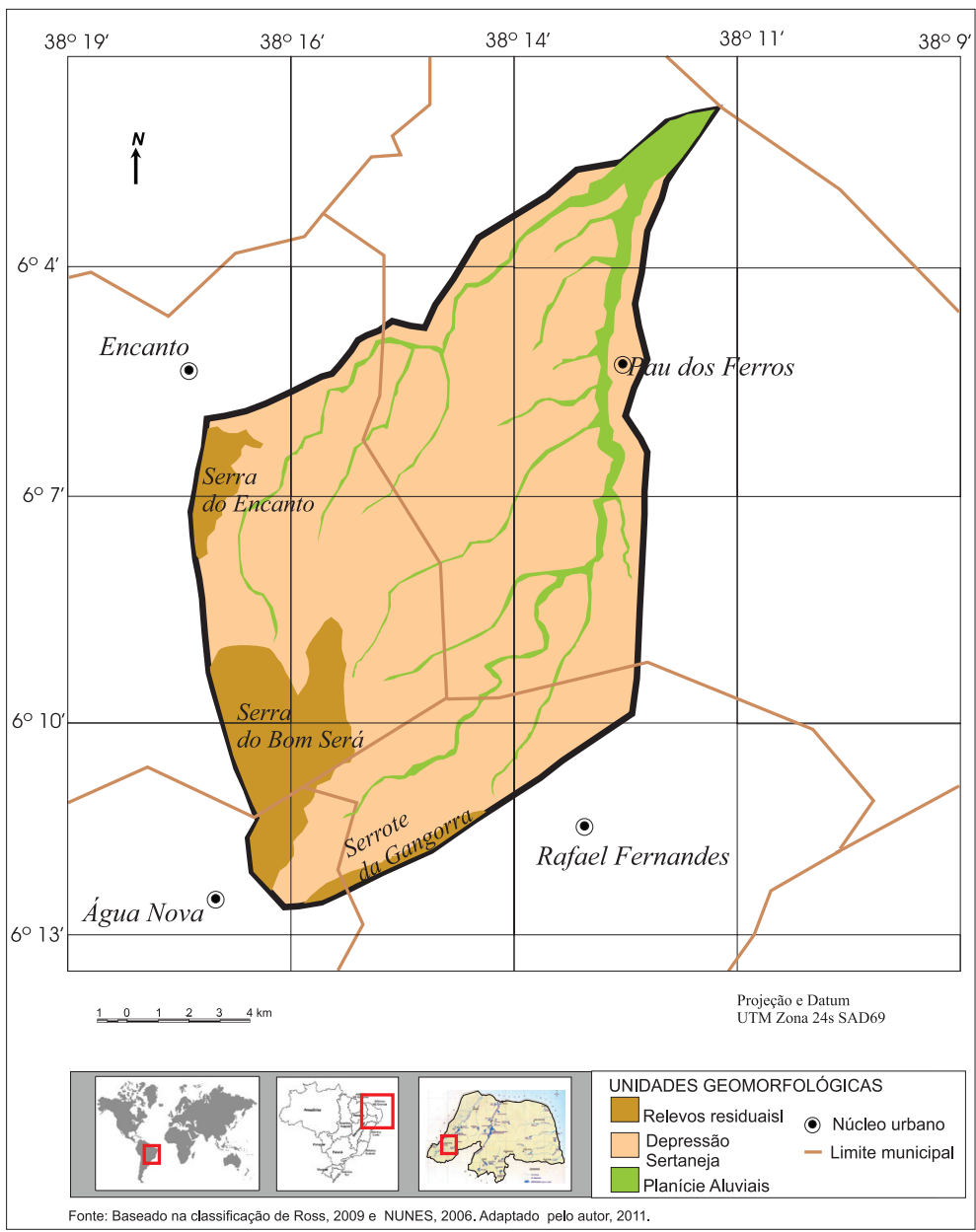

Figura 4 - Geomorfologia da microbacia do riacho Cajazeiras, RN, 2011. 
A fragilidade ambiental representada pela geologia está relacionada ao grau de coesão das rochas, ou seja, à intensidade de ligações entre os minerais que as compõem. Nas rochas pouco coesas prevalecem os processos intempéricos e erosivos (morfogênese), enquanto nas rochas mais coesas prevalece a pedogênese. Aproximadamente 60\% do território potiguar são constituídos por rochas cristalinas do pré-cambriano. As rochas cristalinas ocupam grandes áreas na parte sul do semiárido potiguar, estendendo-se desde o limite da região sedimentar do litoral leste até o extremo oeste, onde o relevo é constituído por serras, inselbergues, serrotes e platôs. Essas rochas apresentam baixa fragilidade ambiental porque apresentam alta coesividade, o que dificulta o intemperismo.

A fragilidade ambiental representada pelo relevo, segundo Tricart (1977), Ab’Saber (1969) e Ross (2003), é crucial na análise integrada da paisagem, porque possibilita que a sociedade use e ocupe a paisagem de forma mais harmônica. A dinâmica do relevo é influenciada pela ação da declividade topográfica. Numa área de declividade suave, quase plana, o intemperismo é forte e o processo erosivo é pequeno. Quando os declives são acentuados, como nas áreas montanhosas e nas escarpas das serras, o processo erosivo é intenso. Neste trabalho, o grau de fragilidade ambiental representado pelo relevo será pautado na declividade conforme mostra a Figura 5.

Nas planícies aluviais a fragilidade ambiental é baixa, pois elas apresentam declividade de $0 \mathrm{a} 4^{\circ}$. Essas áreas servem de proteção à rede fluvial e aos corpos d'água. Cabe ainda ressaltar que essas áreas são protegidas em lei por representar importância ao equilíbrio dinâmico ambiental e social. Em relação aos relevos residuais representados pela Serra do Bom Será, a fragilidade ambiental é considerada média em aproximadamente $70 \%$ de sua área, pois a declividade predominante é de 4 a $20^{\circ}$ os demais $30 \%$ possuem declividade entre 20 e $30^{\circ}$ caracterizando uma fragilidade potencial alta. Na Serra do Encanto a fragilidade ambiental é média em $50 \%$ da área devido à declividade entre 4 e $20^{\circ}$. Na outra porção da serra, a fragilidade é alta em vista da declividade apresentar-se acima de $20^{\circ}$. Compete destacar que a Serra do Encanto apresenta a maior declividade da microbacia, variando entre 30 e $40^{\circ}$. Já o Serrote da Gangorra apresenta baixa fragilidade ambiental, pois a declividade varia entre $0 \mathrm{a}$ $4^{\circ}$ em quase toda sua abrangência. 


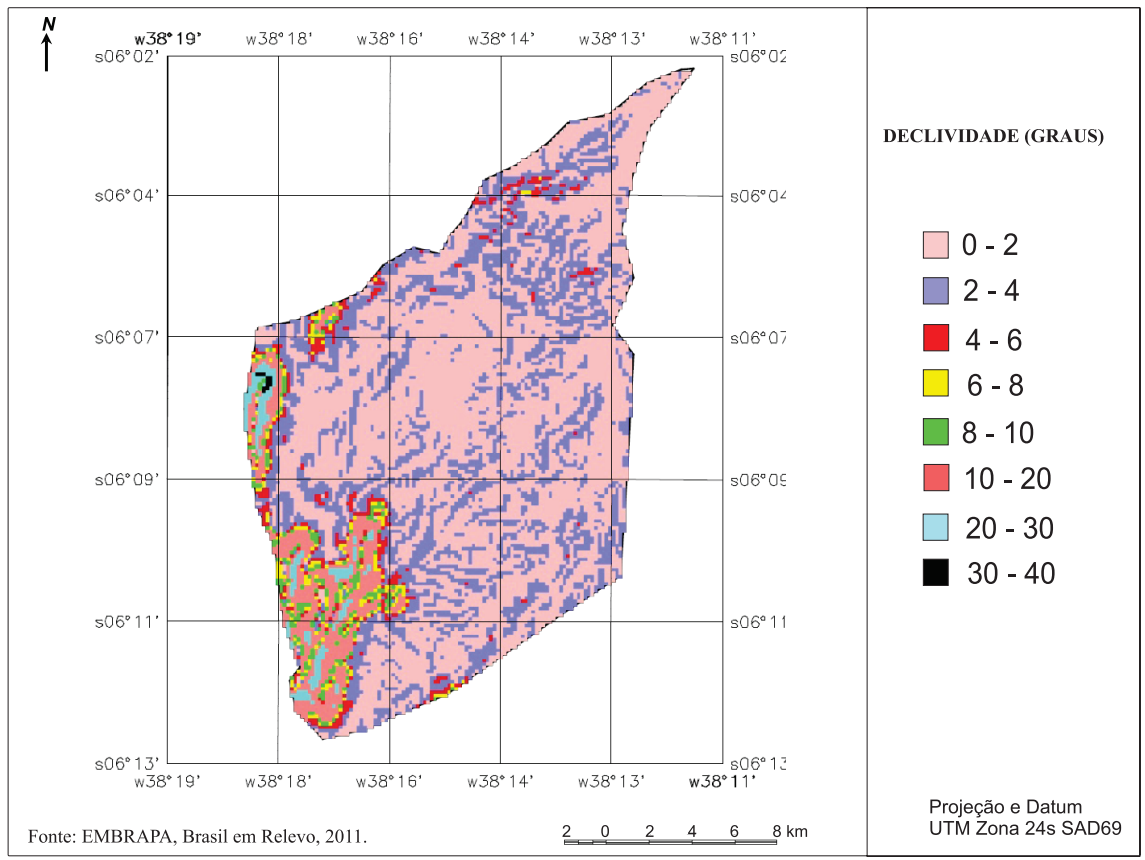

Figura 5 - Declividade da microbacia do riacho Cajazeiras, 2011.

A depressão sertaneja apresenta baixa fragilidade ao processo erosivo em virtude da sua declividade encontrar-se entre 0 a $6^{\circ}$ e, em pequenas áreas (próximo à Serra do Encanto e no baixo do curso do riacho Cachoerinha), apresenta média fragilidade.

A fragilidade dos solos ao processo de degradação, na perspectiva de Tricart (1977), Ross (2009), Guerra e Vitte (2007), Nunes (2006), Ab'Saber (1969), está relacionada à capacidade dos solos de resistir aos processos erosivos. $\mathrm{Na}$ análise da fragilidade do solo, considera-se o grau de maturidade dado pelo produto direto do balanço morfogênese/pedogênese (cf. Figura 6).

Os Solos Aluviais (Neossolos, Embrapa, 2005) estão presentes próximos às margens dos riachos da microbacia. Esses solos, segundo Nunes (2006), são encontrados próximos aos riachos da microbacia, sendo muito utilizados na construção civil e pelos agropecuaristas devido a sua alta fertilidade. Eles apresentam um manto de alteração de alta fragilidade ambiental. 


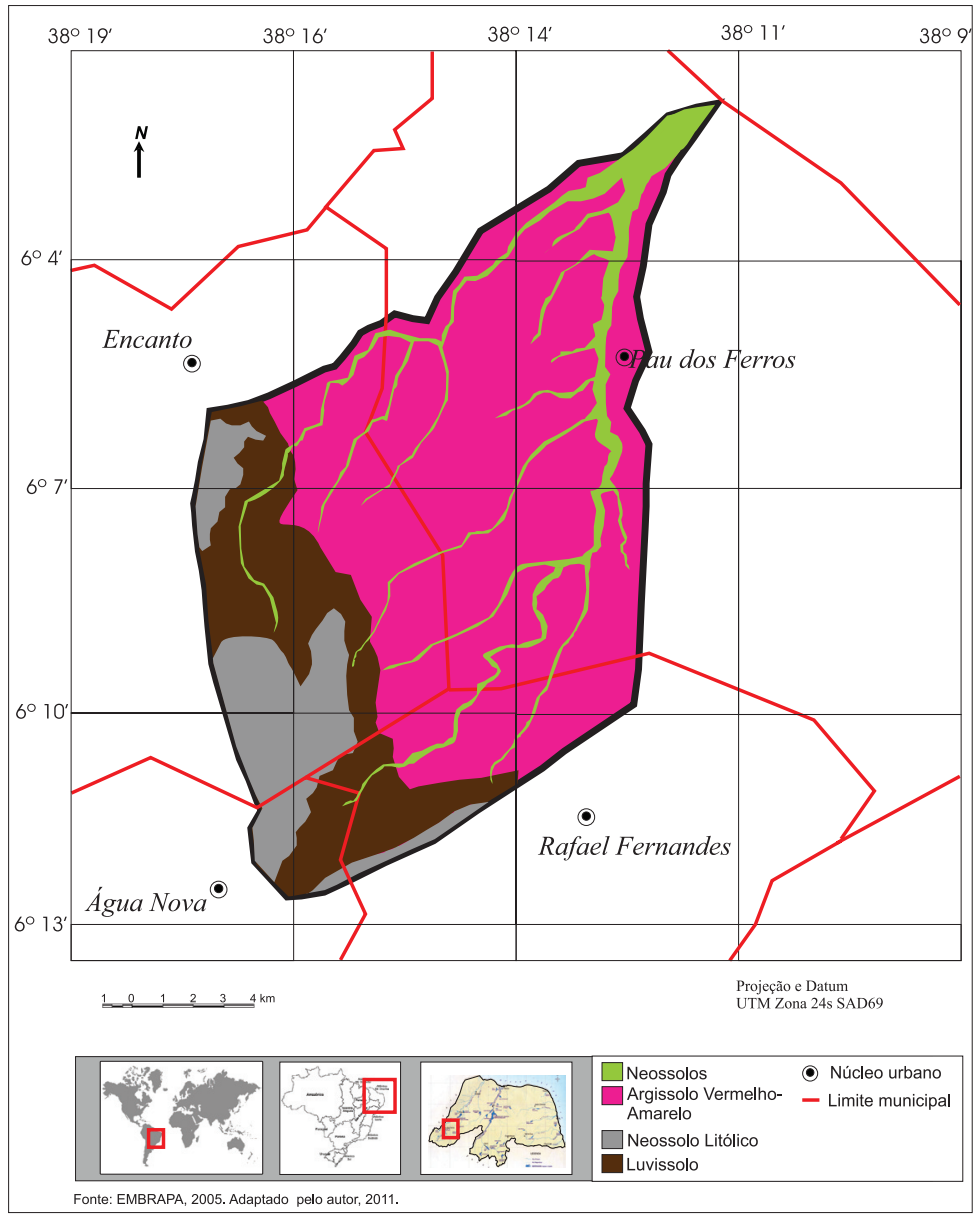

Figura 6 - Pedologia da microbacia do riacho Cajazeiras, RN, 2011.

Os Solos Litólicos (Neossolos Litólicos, Embrapa, 2005) e os Solos Bruno-não-cálcio (Luvissolo, Embrapa, 2005) são encontrados com frequência nos planaltos, colinas cristalinas, serras, serrotes e inselbergues e na depressão sertaneja do semiárido. Esses solos apresentam alta fragilidade ao processo de degradação, principalmente, à erosão, em razão da pouca espessura do solo, variando de rasos a pouco profundos, em torno de $80 \mathrm{~cm}$, e, em muitas áreas do semiárido, de aparecerem juntos a afloramentos e pedregosidades. 
Os Solos Podzólicos Vermelho Amarelo (Argissolo Vermelho-Amarelo, Embrapa, 2005) são solos encontrados na região semiárida nordestina, originários de rochas cristalinas metamórficas. Esses solos variam de profundos a mediano profundos, com horizonte B textural (Bt), vermelho-amarelo, ricos em argila forte a moderadamente drenados, e por apresentarem um horizonte B (Bt) textural argiloso, acabam por apresentar média fragilidade à degradação.

Como resultado da análise dos elementos naturais, obteve-se o mapa da fragilidade potencial ambiental a partir dos elementos geossitêmicos analisados (Figura 7). Os resultados mostram que cerca de $86 \%$ área da microbacia apresenta média fragilidade potencial e outros $14 \%$ apresentam alta fragilidade ambiental potencial. Cabe ressaltar que a alta fragilidade concentra-se nos relevos residuais da Serra do Bom Será, da Serra do Encanto e do Serrote da Gangorra, localizados no alto curso da microbacia.

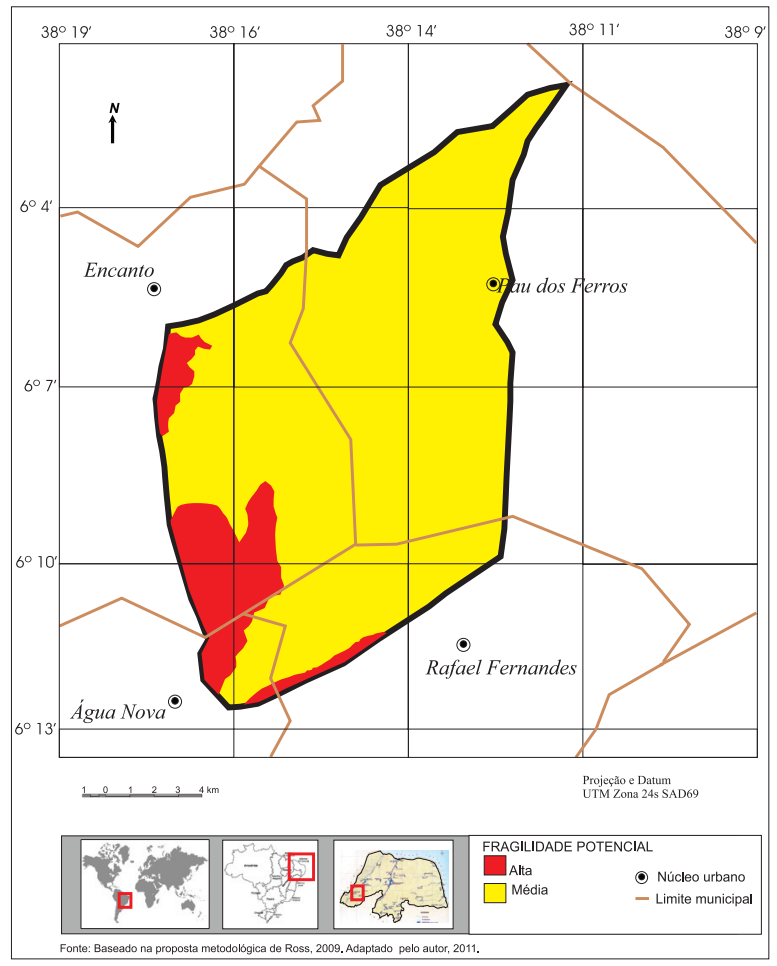

Figura 7 - Fragilidade potencial da Microbacia do riacho Cajazeiras, RN, 2011. 
Fragilidade ambiental emergente

A fragilidade ambiental emergente da paisagem, que é resultado da fragilidade potencial dos elementos naturais somada com as atividades antrópicas, pode ser observada no mapa (Figura 8) de uso e ocupação do solo. Na análise considerar-se-á o uso e a ocupação do solo. Em seguida, apresenta-se o mapa-síntese que mostra a fragilidade emergente da microbacia do riacho Cajazeiras.

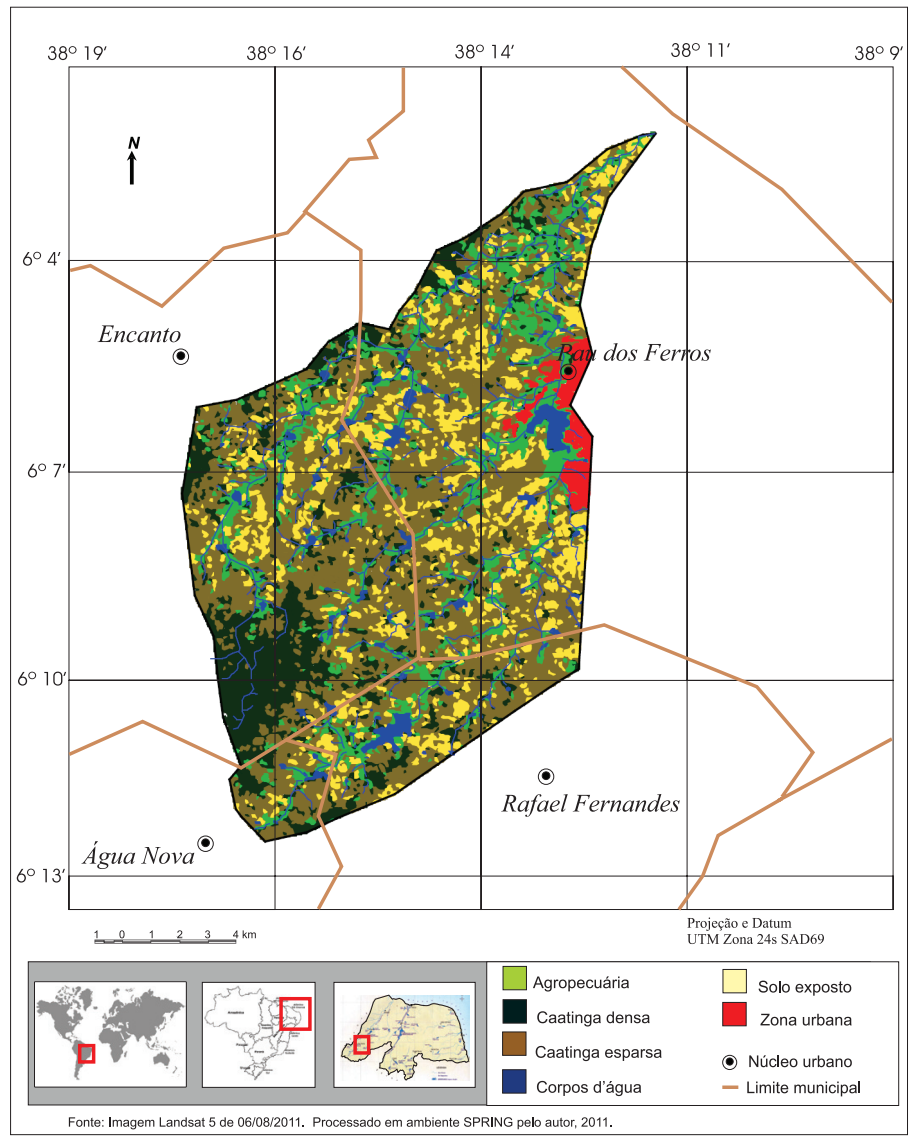

Figura 8 - Uso do solo na microbacia do riacho Cajazeiras, RN, 2011. 
O grau de fragilidade ambiental da paisagem, relacionado ao uso e à ocupação da terra, e à cobertura vegetal, está diretamente ligado à capacidade de proteção da vegetação, aos processos morfogenéticos e pedogenéticos. Nas áreas onde predomina vegetação densa, a fragilidade ambiental diminui, prevalecendo a pedogênese, enquanto que, nas áreas onde a vegetação foi parcialmente ou totalmente suprimida, a fragilidade aumenta, predominando a morfogênese; nas áreas urbanas a erosão é mais intensa por causa do aumento da energia potencial provocada pelas construções, facilitando a morfogênese (cf. Figura 8).

Na área urbana do município de Pau dos Ferros, parte dos esgotos é lançada in natura no principal corpo d'água da microbacia, o Açude 25 de Março, como fora observado no trabalho de campo e também demonstrado no trabalho de Guedes, Maia e Fernandes (2008). Os autores apontaram a poluição nas águas desse açude comprometendo a qualidade ambiental desse corpo d'água e, ainda, comprometendo a qualidade dos hortifrutigranjeiros, o que afeta a sobrevivência de diversos pequenos agricultores vazanteiros e pequenos pescadores.

Nas margens do riacho Cajazeiras, no seu médio curso, e nas margens do riacho do Meio, no seu baixo curso (a partir da parede do Açude 25 de Março o riacho Cajazeiras é chamado riacho do Meio), observou-se em vários pontos a existência de construções irregulares na zona urbana pauferrense, potencializando a fragilidade social e ambiental dessas áreas.

A espacialização identificou que nas unidades serranas da microbacia (Serra do Bom Será, Serra do Encanto e Serrote da Gangorra) apresenta-se média e alta fragilidade ambiental emergente devido à fragilidade dos solos, do clima e da alta declividade presente nessas áreas (cf. Figura 9). Entretanto, alguns pontos dessas áreas foram desmatados para a agricultura e a pecuária, conforme observado na pesquisa de campo e indicado no trabalho de Guedes, Maia e Fernandes (2008). O desmatamento, segundo Tricart (1977), Bertrand (2004), Ab'Saber (1999) e Guerra e Vitte (2007), aumenta significativamente a fragilidade ambiental, porque expõe os solos aos processos erosivos.

Nas áreas da Depressão Sertaneja o grau de fragilidade ambiental mais significativo é o médio, por causa da declividade entre $0^{\circ}$ a $6^{\circ} \mathrm{e}$ da presença dominante de vegetação de caatinga esparsa; entretanto, ressalta-se que essa unidade apresenta uma área significativa de alta fragili- 
lidade ambiental, porque foi identificada uma quantidade considerável de solos expostos em vários pontos da microbacia.

A avaliação da fragilidade ambiental da microbacia do riacho Cajazeiras no semiárido potiguar indica que a situação da paisagem é preocupante em virtude da alta fragilidade emergente representar $33,7 \mathrm{~km}^{2}$ da área, localizada principalmente na planície aluvial, nas áreas serranas e na zona urbana do município de Pau dos Ferros. A média fragilidade emergente foi predominante em 79,6 $\mathrm{km}^{2}$ da área da microbacia destacando-se na área da depressão sertaneja, principalmente no baixo e médio curso e em algumas áreas do alto curso. A microbacia apresentou fragilidade potencial ecológica sensível ao desequilíbrio geossistêmico, predominando a morfogênese, em detrimento da pedogênese. Tal fragilidade da paisagem é intensificada pelo o uso e pela ocupação do solo realizados de forma inadequada às suas características ambientais.

O mapa-síntese da fragilidade ambiental emergente mostrou que as atividades agropecuárias concentram-se próximo das redes fluviais e corpos d’águas da microbacia, não respeitando a legislação ambiental e nem o sistema normativo. Nessas áreas, foram identificados solapamentos dos canais de todos os riachos da microbacia, ravinamentos nas suas margens e vários pontos de desmatamento das matas ciliares.

Os resultados também mostraram que a vegetação é mais densa no alto curso da microbacia nos relevos residuais: Serra do Bom Será, Serra do Encanto e Serrote da Gangorra. O relevo residual mais significativo na paisagem da microbacia é a Serra do Bom Será, que se destaca como o divisor de água mais importante tanto em extensão quanto por ser nascente dos principais riachos da microbacia. A presença da vegetação de caatinga densa, nessas unidades geomorfológicas ou nas outras unidades analisadas, é crucial para o equilíbrio dinâmico e para restringir a fragilidade potencial das unidades físicas e a fragilidade emergente. Diante desse quadro, torna-se necessário implementar soluções para mitigar e corrigir os efeitos provocados pelas atividades econômicas e a expansão urbana, uma vez que não estão em harmonia com o potencial ambiental e social da área de estudo.

Nesse contexto, foram identificados vários problemas que acentuam o processo de degradação e, com isso, aumentam a fragilidade ambiental potencial e emergente evidenciadas na área de estudo. Da mesma forma foi evidenciado, na execução do trabalho de campo e nas entrevistas, o 
uso de agrotóxicos na agricultura de subsistência. Dos 47 entrevistados 90\% sinalizaram a utilização de venenos e outros produtos em suas lavouras. Além disso, foram apontados por todos os entrevistados: a ausência de coleta de lixo na zona rural da microbacia; a presença de um lixão próximo à nascente do riacho Cajazeiras; a inexistência de saneamento básico nas zonas rurais; e o precário sistema de saneamento na zona urbana de Pau dos Ferros.

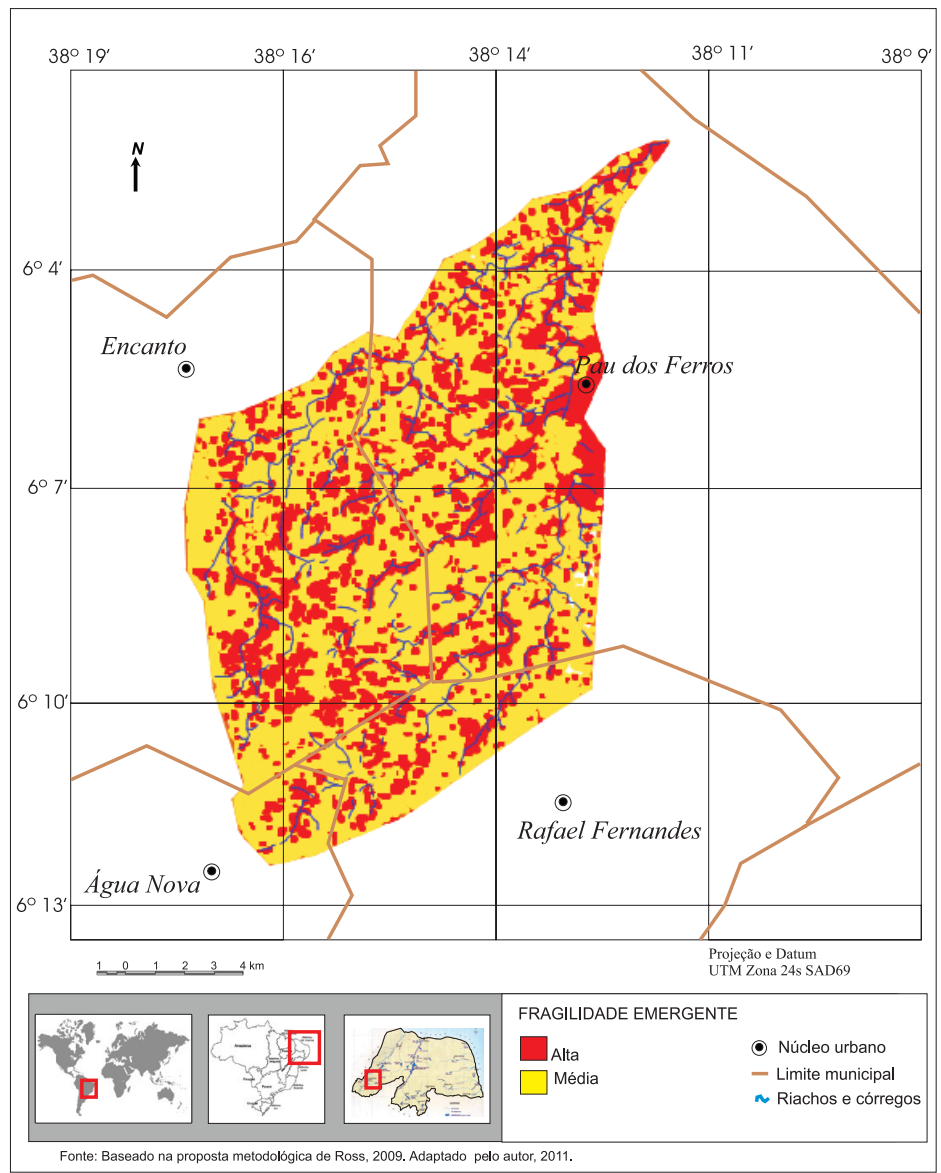

Figura 9 - Fragilidade emergente da microbacia do riacho Cajazeiras, RN, 2011. 


\section{Considerações finais}

A fragilidade ambiental da paisagem da microbacia do riacho Cajazeiras no semiárido potiguar é ampla; as áreas mais frágeis encontram-se espalhadas por toda a microbacia; entretanto, as áreas que apresentam maiores índices de fragilidade estão nas planícies aluviais dos riachos Cajazeiras (riacho do Meio no seu baixo curso), Cachoeirinha, da Favela, dos Estevãos e Boa Sorte. Os graus de fragilidade foram espacializados integrando os dados da fragilidade do clima, da geologia, da geomorfologia (declividade), dos solos, do uso e da ocupação do solo da paisagem.

A metodologia empregada ajudou a compreender a dinâmica da paisagem de forma satisfatória no que se refere ao estudo da fragilidade ambiental potencial e emergente do geossistema. Nesse sentido, como a microbacia do riacho Cajazeiras pertence à bacia do Apodi-Mossoró, torna-se necessário desenvolver um estudo avaliativo das condições socioambientais de toda a bacia hidrográfica. Esse estudo torna-se importante para subsidiar o planejamento territorial da microbacia do riacho Cajazeiras em harmonia com o seu potencial ecológico, social, econômico e cultural. Tais elementos são constitutivos das dimensões que compõem a sustentabilidade.

\section{Referências}

AB'SÁBER, Aziz Nacib. Um conceito de Geomorfologia a serviço das pesquisas sobre o Quaternário. São Paulo: Edusp, IGEOG, 1969. (Série Geomorfologia, 18).

AB'SÁBER, Aziz Nacib. Sertões e sertanejos: uma geografia humana sofrida. Revista Estudos Avançados, v. 13, n. 36, 1999.

BERTRAND, Georges. Paisagem e geografia física global: esboço metodológico. Revista RA'

E GA, Curitiba: Ed. UFPR, n. 8, p. 141-152, 2004. Disponível em: <http://www. nepa.ufma.br/Producao/importantes/paisagem\%20bertrand.pdf>. Acesso em: 7 jun. 2011.

BIGARELLA, João José et al. Estrutura e origem das paisagens tropicais e subtropicais. Contribuição de Everton Passos. Florianópolis: Ed. UFSC, 2003.

CPRM. Serviço geológico do Brasil. Projeto cadastro de fontes de abastecimento por água subterrânea. Recife: CPRM, PRODEEM, 2005.

CREPANI, Edison. Zoneamento ecológico-econômico. In: FLORENZANO, Teresa Galloti (Org.). Geomorfologia: conceitos e tecnologias atuais. São Paulo: Oficina de Textos, 2008. 
EMBRAPA. Brasil em relevo. Campinas: Monitoramento por Satélite, 2005. Disponível em: <http://www.relevobr.cnpm.embrapa.br>. Acesso em: 7 set. 2011.

GUERRA, Antonio José Teixeira; VITTE, Antonio Carlos (Orgs.). Geografia Física no Brasil. 2. ed. Rio de Janeiro: Bertrand Brasil, 2007.

GUEDES, Josiel de A.; MAIA, Jéssica C. L.; FERNANDES, Clefson. Análise da degradação ambiental na microbacia do riacho Cajazeiras, Pau dos Ferros, RN. Anais do II Simpósio de Geografia Física do Nordeste, 2008.

IBGE. Instituto Brasileiro de Geografia e Estatística. Mapa da vegetação brasileira. Rio de Janeiro: IBGE, 2003.

NUNES, José Elias. Geografia física do Rio Grande do Norte. Natal: Imagem Gráfica, 2006.

RODRIGUEZ, José Manuel Mateo; SILVA, Edson Vicente da. A classificação das paisagens a partir de uma visão geossistêmica. Revista Mercator de Geografia da UFC, ano 1, n. 1, 2002.

ROSS, Jurandir L. S. Análise empírica da fragilidade dos ambientes naturais e antropizados. Revista do Departamento de Geografia, n. 8, p. 63-74, São Paulo, USP, 1994.

ROSS, Jurandir L. S. Geomorfologia: ambiente e planejamento. 7. ed. São Paulo: Contexto, 2003.

ROSS, Jurandir L. S. Ecogeografia do Brasil: subsídios para o planejamento ambiental. São Paulo: Oficina de Textos, 2009.

SOTCHAVA, Victor Borisovich. Por uma teoria de classificação de geossistemas da vida terrestre. Biogeografia, São Paulo, n. 14, 1978.

TRICART, Jean. Ecodinâmica. Rio de Janeiro: IBGE, SUPREN, 1977.

José Pio Granjeiro Batista - Possui graduação em Geografia pela Universidade Federal do Rio Grande do Norte e mestrado em Desenvolvimento e Meio Ambiente pela Universidade Federal do Rio Grande do Norte. Atualmente é professor da Secretaria de Estado da Educação e da Cultura do Rio Grande do Norte.

Fernando Moreira da Silva - Possui graduação em Meteorologia pela Universidade Federal da Paraíba, mestrado em Meteorologia Aplicada pela Universidade Federal de Campina Grande, doutorado em Engenharia Mecânica pela Universidade Federal da Paraíba e pós-doutorado em Bioclimatologia da Caatinga. Atualmente é professor da Universidade Federal do Rio Grande do Norte.

Recebido para publicação em 12 de novembro de 2012 Aceito para publicação em 17 de fevereiro de 2013 